\title{
Health life-styles, health concern and social position in Germany and The Netherlands
}

\author{
FRED C.J. STEVENS, JOSEPH P.M. DIEDERIKS, GÜNTHER LÜSCHEN, JOUKE VAN DER ZEE*
}

\begin{abstract}
Based on a telephone survey of 1352 adults in Germany and The Netherlands 3 health life-style dimensions were distinguished and labelled as: i) sobriety (not smoking, healthy food habits and abstinence from alcohol), ii) activity (participation in sports and exercise and low body mass index) and iii) free-living (alcohol consumption, unhealthy food habits and the (un)importance of physical appearance). Gender, age and level of education were much more important predictors of health life-styles than people's concern about their health. In both nations, women compared to men have a more sober, more active and less free-living life-style. In Germany, older persons are more sober, less active and less free-living. In The Netherlands, older persons were less active. A comparison of the results for Germany and The Netherlands suggests that the structural and cultural embeddedness of health life-styles is somewhat different in both nations.
\end{abstract}

Key words: cross-national comparison, health behaviour, health concern, health life-styles, social structure

$-1$ ealth life-styles have been described in many ways. Sometimes they refer to discrete behavioural practices such as smoking or alcohol consumption. Sometimes they refer to patterns of behaviour, for example, risk taking, preventive behaviour or health-protection behaviour. ${ }^{1-4}$ Earlier studies on health life-styles focused mainly on discrete behaviours or practices as risk factors for disease. Recent studies have conceptualized health life-styles not only in terms of possible health risks, but also in terms of increasing an individual's level of well-being, self-actualization and fulfilment. ${ }^{5,6}$

With regard to predictors of health life-styles it has been established that women participate more often in preventive behaviours (e.g. healthy food habits, seat-belt use), while men more often have risky habits such as smoking and alcohol consumption. ${ }^{3,7,8}$ Further, it appears that persons with higher levels of education or higher social status are more involved in health-protection behaviour than persons with low levels of education. ${ }^{7,9}$ Physical activity is more prevalent in younger males while older persons are less physically active, but also consume less alcohol.., 10 While health status appears to be related to health lifestyles few studies have specifically dealt with the question, to what extent does people's concern about their health influence their health life-styles? Also, little is known about health life-styles cross-nationally. Although studies in different countries point to similar results, few were

* F.C.J. Stevens, J.P.M. Diederiks, Department Medical Sociology,

University of Limburg, Maastricht, The Netherlands

G. Lüschen, Heinrich Heine Universität, Düsseldorf, Germany

J. van der Zee, NIVEL, Utrecht, The Netherlands

Correspondence: Dr F.C.J. Stevens, University of Limburg, Department of Medical Sociology, P.O. Box 616, 6200 MD Maastricht, The Netherlands, tel. +3143882204, fax +3143671048 specifically undertaken to compare health life-style patterns across nations. ${ }^{11,12}$

The focus of this paper is i) to explore health life-style patterns cross-nationally and ii) to find out to what extent health life-styles are related to concerns about health and are dependent on position within the social structure.

\section{METHODS}

Data were gathered by telephone interviews in Germany (Northrhine-Westphalia) and in The Netherlands, as part of the 1990 West European Study on Health (WESH), a population survey among adults. A random sample drawn from telephone directories comprised 686 adults in Germany and 666 adults in The Netherlands. Response rates in Germany and The Netherlands were respectively 64 and $49 \%$. The sample consisted of $51 \%$ women in Germany and $56 \%$ in The Netherlands. The mean ages in the samples were 45 (Germany) and 42 years (The Netherlands). A further description of the respondents is presented in table 1 .

\section{Health life-style variables}

Respondents were asked whether they had smoked tobacco or consumed alcohol during the previous 6 months and whether they participated in sports and exercise. In order to distinguish smokers from non-smokers (smoking), drinkers from totäl abstainers (alcohol consumption) and active persons from non-active persons (sports and exercise) the variables were dichotomized ( $1=$ yes, $0=$ no).

The frequency of healthy food habits was obtained by asking respondents, using a 5 point scale i) how regularly they were eating fruit and vegetables and ii) how regularly they were having their breakfast. Respondents answering on both questions 'everyday' or 'often' obtained a score of 1 . 
Respondents answering 'sometimes', 'seldom' or 'never' to 1 or both questions obtained a score of 0 (healthy food habits). As a second measure of food habits, all respondents were asked using a 5 point scale whether they i) consumed chocolate or pastries between meals and ii) consumed chips or french fries between meals. Again, respondents answering both questions 'every day' or 'often' obtained a score of 1 . The remainder scored 0 (snacking between meals). Weight and height were used to compute the body mass index (BMI).

The perception of the importance of physical appearance was measured with a 4 point Guttman scale developed by Cockerham et al. ${ }^{9}$ consisting of 5 items: how important is it for you to i) have a good appearance, ii) look attractive to the opposite sex, iii) have a healthy complexion, iv) have good posture and v) make yourself up so that you 'like yourself' (physical appearance).

\section{Independent variables}

Respondents were asked about their age in years, sex ( 2 =female, $1=$ male) and educational level in years (transformed into quintiles for each country). Employment was measured as a dichotomous variable (employed, part-time or full-time $=1$, unemployed $=0$ ). Respondents were also asked whether they were single or not.

Concerning religion, persons who considered themselves on a 5 point scale as religious or very religious and visited church at least once a week obtained a score of 1 . All others scored 0 .

Table 1 Differences in social position and health concern measures between Germany ( $\mathrm{n}=686)$ and The Netherlands $(\mathrm{n}=666)$

\begin{tabular}{|c|c|c|c|c|c|}
\hline & \multicolumn{2}{|c|}{ Germany } & \multicolumn{2}{|c|}{ The Netherlands } & \multirow[b]{2}{*}{ Significance } \\
\hline & Mean & $\mathrm{SD}$ & Mean & $\mathrm{SD}$ & \\
\hline Gender ( $1=$ male, $2=$ female $)$ & 1.51 & 0.50 & 1.58 & 0.50 & n.s. \\
\hline Age & 45 & 16 & 42 & 16 & $\mathrm{p}<0.001$ \\
\hline Education $(1=$ low, $5=$ high $)$ & 2.70 & 1.34 & 2.94 & 1.42 & $\mathrm{p} \leq 0.05$ \\
\hline Single $(1=$ yes, $0=$ no $)$ & 0.27 & 0.45 & 0.26 & 0.44 & n.s. \\
\hline Work (employment) $(1=y e s, 0=$ no $)$ & 0.56 & 0.50 & 0.49 & 0.50 & $p<0.01$ \\
\hline Religion $(1=$ yes, $0=$ no $)$ & 0.13 & 0.34 & 0.11 & 0.32 & n.s. \\
\hline Perceived health ( $1=\mathrm{bad}, 5=$ excellent $)$ & 3.53 & 1.04 & 3.94 & 0.89 & $\mathrm{p} \leq 0.001$ \\
\hline $\begin{array}{l}\text { Worry about health ( } 1=\text { not at all, } \\
5=\text { very much) }\end{array}$ & 2.91 & 1.23 & 2.36 & 1.16 & $\mathrm{p}<0.001$ \\
\hline Psychological distress $(6=$ low, $30=$ high $)$ & 14.40 & 3.75 & 14.04 & 4.02 & n.s. \\
\hline
\end{tabular}

Table 2 Differences in health behavioural practices and attitudes between Germany $(n=686)$ and The Netherlands $(n=666$ )

\begin{tabular}{|c|c|c|c|c|c|}
\hline & \multicolumn{2}{|c|}{ Germany } & \multicolumn{2}{|c|}{ The Netherlands } & \multirow[b]{2}{*}{ Significance } \\
\hline & Mean & $\mathrm{SD}$ & Mean & $\mathrm{SD}$ & \\
\hline Alcohol consumption $(1=$ yes, $0=$ no $)$ & 0.85 & 0.35 & 0.80 & 0.40 & $p<0.01$ \\
\hline Smoking $(1=$ yes, $0=$ no $)$ & 0.39 & 0.49 & 0.34 & 0.47 & $p<0.05$ \\
\hline Healthy food habits ( $1=$ yes, $0=$ no) & 0.69 & 0.46 & 0.74 & 0.44 & n.s. \\
\hline Snacking between meals $(1=$ yes, $0=$ no $)$ & 0.72 & 0.45 & 0.69 & 0.46 & n.s. \\
\hline Sports and exercise $(1=$ yes, $0=$ no $)$ & 0.64 & 0.48 & 0.56 & 0.50 & $p<0.01$ \\
\hline Body mass index & 24.24 & 3.60 & 23.76 & 4.10 & $p<0.05$ \\
\hline $\begin{array}{l}\text { Physical appearance ( } 4=\text { unimportant, } \\
12=\text { very important) }\end{array}$ & 8.46 & 1.73 & 8.69 & 1.64 & $p<0.05$ \\
\hline
\end{tabular}

Perceived health (health perception) was measured by asking respondents how they rated their health using a 5 point scale. Psychological distress was measured using a depression and anxiety scale developed by Cockerham et al. ${ }^{13}$, comprising 6 items, 3 on depression and 3 on anxiety (Cronbach's $\alpha=0.71$ ). Finally, all respondents were asked how much they worried about their health, with scores ranging on a 5 point scale between 'very much' and 'not at all'. Due to strong intercorrelations among the variables worrying about health, psychological distress and perceived health, the factor scores were used as 1 health concern measure in subsequent analyses.

\section{RESULTS}

From table 1 it appears that the Germans perceive their health as worse than the Dutch and also worry more about their health. There are no differences in psychological distress.

It also appears that the Germans, on average, consume alcohol more often, participate more often in sports and exercise, smoke more frequently than the Dutch and have a higher BMI (table 2). The Dutch pay more attention to physical appearance. There are no differences in food habits between both samples.

Dimensionality of health life-styles

In order to explore life-style dimensions, a principal component analysis was run on the 7 health behaviour and health attitude variables described above (table 3 ). The analysis for Germany and The Netherlands combined, reveals a first component with high loadings on the variables (not) smoking, healthy food habits and (not) consuming alcohol. This component is likely to indicate a life-style dimension in which soberness, especially with regard to drinking behaviour, smoking and eating is dominant.

The second component has high loadings on the variables participation in sports and exercise and BMI (negative). This indicates that activeness and slenderness are important characteristics of this life-style component. The third component, with high loadings on the (un)importance of physical appearance, consumption of alcohol and (unhealthy) eating between meals suggests the contrast with the 2 other health life-style dimensions. High scores on this compo- 
nent indicate a life-style with little concern about how to look (physical appearance), what to eat or what to drink. Separate analyses of the German and Dutch data indicate slight differences between the samples. It appears that alcohol consumption only has a high loading on the first component for the Dutch sample. The loading of physical appearance is relatively low in the German sample.

Summing up, the components point to 3 health life-style behavioural patterns: a health life-style pattern in which abstinence is dominant (sobriety), one with activity and slenderness as the main focus and one in which indulgence seems to be the key element (free-living). Based on the results for Germany and The Netherlands combined, 3 scale scores were calculated. In order to have uncorrelated life-style dimensions, factor scores were made and labelled as sobriety, activity and free-living.

\section{Predictors of health life-styles}

In order to explore predictors of health life-styles, regression analyses were run. Table 4 shows that for both samples gender is the strongest predictor of the sobriety life-style dimension. Both in Germany and The Netherlands women and persons with strong religious orientations have more sober life-styles (eating, smoking and drinking behaviour) than men or persons with less strong religious orientations. In the German sample, older persons have more sober life-styles than younger persons. Health concern, however, does not predict differences in sobriety health life-style.

In the analyses with the activity life-style dimension as the dependent variable, it appears that, both in Germany and The Netherlands, age is the strongest predictor, followed by level of education and gender. That is, younger persons, higher educated persons and women are more often characterized by a health life-style of activity and slenderness than older persons, men and lower educated persons. In the German sample it further appears, that persons who are concerned about their health tend to be less active. Apparently, health concern is more often a hindrance than an inducement to being active.

With regard to the free-living life-style dimension, it appears that gender and age are the strongest predictors, that is, men and younger persons (in Germany) tend to adopt a more free-living life-style than women and older persons. It further appears that in the Dutch sample health concern is negatively related to the free-living health life-style dimension. This is in the expected direction: persons who are concerned about their health are less

Table 3 Principal component analysis on 7 health behaviour and attitude variables (varimax rotation, $n=1,352$ )

\begin{tabular}{lccccccccccccc}
\hline & \multicolumn{3}{c}{ Total $(\mathrm{n}=1,352)$} & \multicolumn{4}{c}{ Germany $(\mathrm{n}=686)$} & \multicolumn{4}{c}{ The Netherlands (n=666) } \\
& Comm* & \multicolumn{1}{c}{ I } & \multicolumn{1}{c}{ II } & III & Comm* & I & II & III & Comm* & I & II & III \\
\hline Healthy food habits & 0.44 & 0.60 & 0.22 & -0.16 & 0.44 & 0.15 & 0.63 & -0.15 & 0.41 & 0.50 & 0.33 & -0.22 \\
Smoking (not) & 0.68 & 0.80 & -0.02 & 0.20 & 0.67 & -0.09 & 0.80 & 0.13 & 0.64 & 0.75 & 0.11 & 0.26 \\
Alcohol consumption & 0.51 & -0.41 & 0.33 & 0.47 & 0.55 & 0.26 & -0.16 & 0.68 & 0.48 & -0.64 & 0.20 & 0.16 \\
Sports and exercise & 0.56 & 0.16 & 0.71 & 0.16 & 0.54 & 0.70 & 0.13 & 0.17 & 0.59 & 0.03 & 0.77 & 0.03 \\
Body mass index & 0.45 & 0.00 & -0.65 & 0.14 & 0.58 & -0.75 & 0.04 & 0.10 & 0.35 & -0.00 & -0.59 & 0.01 \\
Physical appearance & 0.49 & -0.05 & 0.31 & -0.62 & 0.28 & 0.24 & 0.28 & -0.38 & 0.66 & -0.13 & 0.22 & -0.78 \\
Snacking between meals & 0.41 & 0.01 & 0.11 & 0.63 & 0.51 & -0.05 & 0.16 & 0.69 & 0.43 & -0.19 & 0.22 & 0.59 \\
& & & & & & & & & & & & & \\
Eigen value & 1.30 & 1.18 & 1.05 & 1.31 & & 1.31 & 1.22 & 1.04 & & 1.32 & 1.15 & 1.09 \\
Percentage explained & & $19 \%$ & $17 \%$ & $15 \%$ & & $19 \%$ & $17 \%$ & $15 \%$ & & $19 \%$ & $17 \%$ & $16 \%$ \\
\hline
\end{tabular}

* Comm: Communality

Table 4 Regression analysis with health life-styles as dependent variables and health concern and social structural variables as independent variables for Germany ( $n=686)$ and The Netherlands $(n=666)$ (zero-order correlations and $\beta$-coefficients)

\begin{tabular}{|c|c|c|c|c|c|c|c|c|c|c|c|c|}
\hline & \multicolumn{4}{|c|}{ Sobriety } & \multicolumn{4}{|c|}{ Activity } & \multicolumn{4}{|c|}{ Free-living } \\
\hline & \multicolumn{2}{|c|}{ Germany } & \multicolumn{2}{|c|}{ The Netherlands } & \multicolumn{2}{|c|}{ Germany } & \multicolumn{2}{|c|}{ The Netherlands } & \multicolumn{2}{|c|}{ Germany } & \multicolumn{2}{|c|}{ The Netherlands } \\
\hline & $\mathrm{r}$ & $\beta$ & $\mathrm{r}$ & $\beta$ & $\mathrm{r}$ & $\beta$ & $\mathrm{r}$ & $\beta$ & $\mathrm{t}$ & $\beta$ & $\mathrm{r}$ & $\beta$ \\
\hline Health concern & -0.04 & -0.06 & -0.02 & -0.02 & -0.15 & $-0.10^{b}$ & -0.06 & -0.05 & -0.03 & 0.03 & -0.14 & $-0.10^{b}$ \\
\hline Age & 0.14 & $0.14^{b}$ & 0.06 & 0.04 & -0.33 & $-0.28^{\mathrm{c}}$ & -0.30 & $-0.21^{c}$ & -0.23 & $-0.13^{\mathrm{a}}$ & -0.15 & -0.07 \\
\hline Gender (women) & 0.25 & $0.24^{c}$ & 0.25 & $0.23^{c}$ & 0.09 & $0.14^{\mathrm{c}}$ & 0.09 & $0.13^{b}$ & -0.24 & $-0.19^{\mathrm{c}}$ & -0.25 & $-0.22^{c}$ \\
\hline Education & -0.01 & 0.07 & -0.02 & 0.06 & 0.25 & $0.17^{\mathrm{c}}$ & 0.27 & $0.21^{c}$ & 0.19 & $0.09^{\mathrm{a}}$ & 0.14 & 0.04 \\
\hline Work (employment) & -0.12 & 0.01 & -0.16 & -0.08 & 0.10 & -0.06 & 0.12 & 0.02 & 0.22 & $0.10^{\mathrm{a}}$ & 0.13 & 0.02 \\
\hline Single & -0.05 & 0.04 & 0.01 & 0.03 & 0.22 & 0.04 & 0.16 & 0.02 & 0.15 & 0.03 & 0.17 & $0.12^{b}$ \\
\hline Religion & 0.20 & $0.16^{\mathrm{c}}$ & 0.13 & $0.11^{b}$ & -0.07 & -0.03 & -0.08 & 0.01 & -0.08 & -0.02 & -0.05 & -0.00 \\
\hline $\mathrm{R}^{2}(\mathrm{adj})$ & & 0.10 & & 0.07 & & 0.16 & & 0.13 & & 0.11 & & 0.10 \\
\hline
\end{tabular}


inclined to adopt a free-living health life-style. Finally, in the German sample persons who are employed part-time or full-time have a higher score on the free-living health life-style dimension.

\section{CONCLUSIONS AND DISCUSSION}

An analysis has been presented of health life-styles in Germany and The Netherlands. Life-styles were empirically distinguished into 3 components, labelled as sobriety, activity and free-living. Sobriety mainly comprised not smoking, abstinence from alcohol and practising healthy food habits. The activity health life-style dimension was indicated by the participation in sports and exercise and a low BMI. In this dimension physical activity and slenderness appear to be the key elements. Finally, the free-living health life-style dimension mainly consisted of eating sweets, chips, french fries, etc., between meals, consuming alcohol and considering physical appearance as unimportant. In this dimension the indulgence of all kinds of appetites appears to be dominant.

In Germany, alcohol consumption was part of the freeliving life-style component, while in The Netherlands it was part of the sobriety life-style component. In The Netherlands, it appears to be associated with abstinence of certain behaviours. In Germany, however, alcohol consumption was part of a more indulgent life-style.

With regard to the predictors of health life-styles, the main finding of the study is that status and position in the social structure are more important predictors than concern about health. Health concern only relates to the activity health life-style dimension in the German sample and to the free-living life-style dimension in the Dutch sample. In The Netherlands, persons who are concerned about their health are less inclined to adopt a free-living life-style. In Germany, people who are concerned about their health have a lower activity life-style score. In other words, it appears that health concern probably does not lead to more activity, but to less activity. In The Netherlands, however, health concern is indeed related to less indulgence. Why this is only the case in The Netherlands and not in Germany is not clear. It suggests, that the Dutch tend to behave more healthily than the Germans.

The most consistent finding of the study is that in both Germany and The Netherlands gender is strongly related to all health life-style dimensions, women compared to men report being more sober in their life-style patterns, less free-living and more active. For the gender differences in the sobriety dimension a possible explanation might be that women perform more traditional roles in which soberness is an important aspect. The fact that religious persons also have higher sobriety scores underscores the importance of tradition with regard to the sobriety health life-style.
Several limitations of the study should be mentioned. Firstly, only a limited number of health practices were used to construct health life-style components. Secondly, the use of telephone interviews limits the sample to persons with a telephone in their household. However, as the telephone coverage in both nations is quite high (approximately 95\%) we do not expect that this has led to a disproportionate underrepresentation of persons of lower income groups. Thirdly, the rather low response rate may have consequences for the generalizability of the results. Consistency of findings with other studies and across both nations, however, do not suggest that this may have a strong negative effect on the results.

This study was not designed to test possibilities for health prevention. The fact, however, that health concern compared to position within the social structure was only a modest predictor of health life-styles underscores the difficulty of influencing health life-styles.

\section{REFERENGS}

1 Harris DM, Guten S. Health-protective behavior: an exploratory study. J Hith Soc Behav 1979;20:17-29.

2 Mechanic D, Cleary PD. Factors associated with the maintenance of positive health behavior. Prev Med 1980;9:805-14.

3 Langlie JK. Interrelationships among preventive health behaviors: a test of competing hypotheses. Public Hlth Rep 1977;94:216-25.

4 Vickers RR, Conway TL, Hervig LK. Demonstration of replicable dimensions of health behaviors. Prev Med 1990;19:377-401.

5 Pender NJ. Health promotion in nursing practice. Norwalk, CT: Appleton, 1987.

6 Walker SN, Sechrist KR, Pender N. The health-promoting lifestyle profile: development and psychometric characteristics. Nursing Res 1987;36:76-81.

7 Gottlieb NH, Green LW. Life events, social network, lifestyle, and health: an analysis of the 1979 National Survey of Personal Health Practices and consequences. HIth Edu Q 1984;11:91-105.

8 Gottlieb NH, Baker JA. The relative influence of health beliefs, parental and peer behaviors and exercise program participation on smoking, alcohol use and physical activity. Soc Sci Med 1986;22:915-27.

9 Cockerham WC, Kunz G, Lüschen G. Social stratification and health lifestyles in two systems of health care delivery: a comparison of the United States and West Germany. $J$ HIth SoC Behav 1988;29:113-26.

10 Prohaska TR, Levental EA, Leventhal H, Keller ML. Health practices and illness cognition in young, middle aged and elderly adults. J Gerontol 1985;40:569-78.

11 Abel T. Measuring health lifestyles in comparative analysis: theoretical issues and empirical findings. Soc Sci Med 1991;32:899-908.

12 Lüschen G, Cockerham WC, Kunz G. Health and illness in America and Germany. Munchen: Oldenbourg, 1989.

13 Cockerham WC, Kunz G, Lüschen G. Psychological distress, perceived health status, and physician utilization in America and West Germany. Soc Sci Med 1988;26:829-38.

Received 13 July 1993, accepted 24 January 1994 